\title{
Home Language-Learning Strategies Chosen by Chinese Immigrant Families
}

\author{
Shikun $\mathrm{Li}^{1}$ \\ ${ }^{1}$ School of Foreign Languages and Cultures, Nanjing Normal University, Nanjing, China \\ Correspondence: Shikun Li, School of Foreign Languages and Cultures, Nanjing Normal University, Wenyuan Rd \\ No.1, Nanjing, China. E-mail: yw_1@vip.126.com
}

Received: June 6, $2020 \quad$ Accepted: July 11, $2020 \quad$ Online Published: July 14, 2020

doi:10.5539/ijel.v10n5p155 URL: https://doi.org/10.5539/ijel.v10n5p155

\begin{abstract}
The home context is ranked as one of most essential factors in heritage-language maintenance. Compared to many other ethnic minority groups, the Chinese community is always underrepresented in bilingual-education research. This case study explores language learning in the home context in two Chinese immigrant families. Both sets of parents share a similar cultural background and socioeconomic status in the U.S. However, one family relies heavily on technology to promote their child's literacy development at home, while the other family prefers to increase cultural-immersion opportunities for their child. In addition to presenting different home-learning strategies used by Chinese parents, the present study explores factors that affect strategy selection. The results suggested that three factors impact Chinese parents' selection of language-learning strategies: 1) the influence of individual ethnic communities; 2) parents' perceptions of their heritage languages; and 3) social validation from people outside the home community. This paper will discuss the distinctive home context and its implications for heritage-language maintenance.
\end{abstract}

Keywords: Chinese-heritage learner, parents' involvement, language-learning strategies

\section{Introduction}

In the U.S., the Chinese community is an expansive construct with diverse characteristics. Compared to many other ethnic minority groups, the Chinese community is always underrepresented in bilingual studies (Wang, 2003). However, U.S. Census statistics suggest a rapid increase in the number of Chinese-heritage learners (CHLs) in the U.S, which calls for a corresponding increase in teachers capable of accommodating the needs of CHLs in the classroom. Most studies refer to learners who enroll in Chinese-heritage schools as "Chinese-heritage learners" (Cheng, 2012; Gu, 2012; Li, 2013). In the present study, a Chinese-heritage learner $(\mathrm{CHL})$ is defined as "a language student who is raised in a home where a non-English target language is spoken and who speaks or at least understands the language and is to some degree bilingual in the heritage language and in English" (He \& Xiao, 2008, p. 6).

Many Chinese immigrant families perceive home as a secondary classroom, which can accelerate their children's acquisition of Chinese. Many CHLs begin their language development in a family or community context (Li, 2005) and enter formal school settings holding prior knowledge, gained from such contexts. Such knowledge is also referred to as a "fund of knowledge" (Marsh \& Turner-Vorbeck, 2010). When CHLs grow up in homes in which Chinese culture is celebrated, they tend to exhibit a positive attitude towards Chinese learning in the classroom (Chen, 2001; Budiyana, 2017). It is thus clear that active parental involvement has a significant impact on heritage-language maintenance (Li, 1999; Li, 2004; Ji \& Koblinsky, 2009; Lawton \& Logio, 2009).

Although previous researchers have argued that the home context has a crucial impact on heritage-language maintenance among CHLs, few studies have examined the language-learning choices of parents in Chinese immigrant families or the factors that impact learning choices. To bridge the existing research gap and help teachers understand the funds of knowledge held by CHLs, this study investigates the efforts of two different Chinese heritage families to promote Chinese acquisition at home.

\section{Literature Review}

\subsection{The History of Chinese Heritage Education}

The history of Chinese-language schools in the United States can be traced back to 1848, when the practice of 
importing Chinese laborers began (Chao, 1996; Wang, 1996; Cheng, 2012). In the U.S., Chinese-heritage schools did not appear until the middle of the 19th century (see Lai, 2000; Cheng, 2012; Gu, 2011). After World War II, Chinese immigrants from Taiwan and Hong Kong established community-based Chinese-heritage schools to ensure that their children were able to maintain their heritage languages and cultures (Wang, 1996; Cheng, 2012). Initially, these schools were small; most were church-based or family-oriented (Wang, 2003). It was not until the late twentieth century that Chinese-heritage schools began to purchase their own school buildings (Wang, 1996; Cheng, 2012; Gu, 2011).

Most Chinese-heritage schools in the U.S. were nonprofit organizations, operated entirely by volunteers (Wang, 2003). These volunteers were trained teaching staff, as well as voluntary administrators or board members (Chao, 1996; Cheng, 2012). As the schools expanded, their student bodies grew and they acquired more educational equipment. These changes were aligned with the growth in the number of new immigrants from mainland China (Wang, 1996; Gu, 2012).

In 2012, there were over 1,000 Chinese-heritage schools in the U.S., according to research conducted by the Chinese Heritage Language Education and Research Project (see Cheng, 2012). Nowadays, large Chinese-heritage schools in California have estimated average enrollments of more than 2,000 per school. In some school districts in northeastern California, learners can earn academic credits by attending Chinese-heritage schools (Cheng, 2012; Gu, 2012). However, most Chinese-heritage schools remain independent of the formal education system.

\subsection{The Role of Parental Involvement in the Academic Success of CHLs}

In the Chinese community, the role of the home context remains controversial. For decades, Chinese-American mothers have been labeled "tiger moms", for their relatively authoritarian parenting style. An authoritarian parenting style is generally believed to reflect an "obsess[ion] with power control" (Baumrind, 1971). For this reason, Chinese-American parents, not wishing to be seen as power-control obsessed, are changing their parenting styles. Some have adopted an authoritative parenting style that emphasizes "sharing power with other family members" in the home (Baumrind, 1971).

Early research suggests that authoritative (as opposed to authoritarian) parenting styles can improve a child's future academic success (Baumrind, 1972). However, contemporary researchers have argued that Baumrind's (1971) findings on the relationship between authoritative parenting styles and children's academic outcomes are controversial (see Chao \& Tseng, 2002). Chao and Tseng (2002) have suggested that Asian-American adolescents who maintain the highest grades have parents who demonstrate an authoritarian style. The debate over which parenting style is more effective therefore continues.

Nonetheless, a clear correlation exists between parental involvement and children's literacy development, as many researchers have consistently confirmed (Budiyana, 2017; Cunningham, 2011; Li, 2003; Tse, 2001; Park \& Sarkar, 2007). Studies have also shown that Asian-American parents demonstrate a more intensive involvement in their children's education than parents from other language-minority groups, such as Latino or African-American parents. Most Asian-American parents believe that such efforts will enable their children to achieve academic success, despite cultural and language barriers (Sohn \& Wang, 2006).

\subsection{Chinese Parental Involvement and Heritage Language Maintenance}

Non-native-English-speaking parents may not imbue their children with family values if heritage languages are unavailable at home (Feinberg, 2002). Similarly, it is easier for children to absorb family values when immigrant families deeply appreciate their heritage language. Immigrant parents who wish to maintain heritage languages begin heritage-language immersion much earlier than those who do not (Li, 2005). Kondo-Brown (2006) has shown that, when a child with foreign-born parents begins to socialize outside the home in the dominant language, the first non-dominant language that child acquires (also referred to as the "mother tongue" or "first language") may gradually become secondary. A stronger language connection between heritage learners and their home contexts gives learners a more positive perception of the heritage language.

Although extensive research has shown that most Chinese immigrant parents hold positive attitudes towards heritage-language education (e.g., Lao, 2004), the ways that Chinese parents translate their language-learning beliefs into home practices and the reasons for making those choices are not well understood. To obtain a comprehensive understanding of the academic involvement of CHL parents, this ethnographic case study of two Chinese immigrant families attempts to answer the following research questions:

1) What type of language-learning strategies do Chinese parents use at home?

2) What factors influence the parents' choice of language-learning strategies at home? 


\section{Method}

\subsection{Participants}

Although they represent different types of immigrant families, the parents who participated in this research are quite similar from a socioeconomic perspective. They were born and raised in Mainland China and came to the U.S. to pursue advanced academic degrees. All are green-card holders, who prefer to be referred to as "Chinese" rather than "Chinese-American."

Both immigrant families have one Chinese-heritage learner. Both CHLs are 12 years old and enrolled in different public elementary schools. The two Chinese-heritage learners attend the same class at a Chinese-heritage school in the northeastern U.S. According to their parents, both CHLs began to learn their heritage language at roughly the same time. The rationale for recruiting 12-year-old heritage learners is Chinen and Tucker's (2006) finding that heritage learners develop a form of ethnic awareness (e.g., understanding ethnic stereotypes), which they need to develop an ethnic identity in the future, at approximately the age of twelve.

\subsection{Research Instrument}

Six semi-structured interviews with each family were used to collect data on parental involvement with the CHLs. Compared to structured interviews, the semi-structured interviews gave the participants more flexibility to elaborate on their beliefs about language-learning strategies (Glesne, 2011). The semi-structured interviews included questions exploring: 1) language-learning strategies at home, and 2) the factors that influenced the choice of language-learning strategies.

Before the interviews, the researcher regularly visited the participants' homes and established a positive relationship with the participants. All six semi-structured interviews were conducted at the participants' homes. The researcher began the interviews by introducing the purpose of the study, followed by the implications of the research results, and the researcher's profile. After obtaining informed consent from all participants, the researcher recorded the interviews. All of the interview questions were initially written in Chinese and then translated into English. A voice memo was also recorded for each interview, once it was completed. The voice memos gave the researcher an opportunity to reflect on the behavior of interviewer and interviewees.

\subsection{Data Analysis}

The qualitative-data analysis included the following four steps: 1) enriching the source of the data, 2) coding, 3) cataloguing the categories, and 4) writing the results. Initially, the primary qualitative dataset included formal interviews and informal conversations between the researcher and participants, reflective memos, and notes from the home visits. Strategies, such as annotation, were used to enrich the raw dataset before the coding began.

All of the interview and voice memos were coded using Nvivo 11. Descriptive notes were used to profile the participants and to categorize their attributes (e.g., age, gender, socioeconomic status, language ability, educational background, etc.). The final profiles were reviewed by the participants to avoid any misunderstandings or misinterpretations. The code schema was developed based on the research questions. Keywords such as "home-language support", "extra-curricular language assignment", and "interaction with the ethnic community" were highlighted during the coding. The last step during coding was cataloguing categories. Three categories were established: 1) teaching strategies that focused on developing a positive linguistic/cultural environment at home; 2) teaching strategies that encouraged active involvement in the community; and 3) teaching strategies intended to promote the early establishment of a child's ethnic identity. This three-step coding process helped the researcher to identify patterns in parental teaching practices, while also obtaining a deeper understanding of each Chinese immigrant family. The results are presented in the following section.

\section{Results}

\subsection{Zhang's Mother's Language-Learning Strategies at Home}

Zhang's mother is a single mother, who moved to the U.S. after obtaining her bachelor's degree in China. The purpose of her move was primarily academic. She later obtained her Master's degree in Teaching English as a Second Language (TESOL) from a U.S. public university and is currently working as a supplementary teacher at a local middle school in the northeastern U.S. She perceives herself as bilingual in Mandarin and English. Zhang is a sixth-grade student at a local elementary school. According to her mother, Zhang started to learn Chinese at a very early age. For the past three years, Zhang has attended the local Chinese-heritage school every Friday to receive formal instruction in the Chinese language. Zhang's mother is very pound of Zhang's positive attitude towards Chinese learning: "[Zhang] loves to tell me about what she has learned at school and how other students behave at school, too. And I could tell from her words that she enjoys learning Chinese and making new friends 
at the Chinese school." Zhang's mother felt that two hours' study at the local Chinese-heritage school were not enough for Zhang to develop literacy capacity: "I have observed some of the classes, and I found that teachers at the Chinese school prefer to ask students questions orally, instead of letting [the students] write down the answers. My daughter's oral Chinese is already pretty good, as well as her listening skills, so I wish teachers could spend more time on developing students' reading and writing skills."

At home, Zhang's mother believes that the most effective language-learning strategy is to significantly increase Zhang Chinese homework. During the interviews, she insisted that the amount of homework was closely tied to academic success and that the homework assigned by the Chinese-heritage school was insufficient. For this reason, Zhang's mother constantly downloaded extra reading and writing tasks from the Internet: "Sometimes, when a friend or a relative goes back to China, I will ask him or her to bring back some Chinese elementary school language exercise books. [...] It helps, too." Zhang's mother hopes that her daughter's language awareness will improve if she completes extra homework. She also invests a lot of time in supervising her daughter's studies at home. According to Zhang's mother, it is necessary to supervise her daughter's studies in order to identify Zhang's learning deficiencies.

Zhang's mother uses digital devices to promote her daughter's interest in learning Chinese. "Zhang is a quiet child, and she enjoys being alone and doing her stuff. But I know how much she likes an iPad. Therefore, I promised to buy her an iPad as long as she promises to use it for learning." Zhang's mother also mentioned some iPhone applications that motivated Zhang to learn Chinese. Most of the applications integrated language practice and games. Zhang also watched Chinese movies and cartoons to learn Chinese at home. They "[...] familiarize Zhang with Chinese history and culture" said her mother.

"I love the idea that learning should be fun," Zhang's mother concluded at the end of one interview. "Therefore, I think I have put a lot of effort into letting Zhang realize how much fun she would have if she works hard at learning Chinese. And I am sure that Zhang understands how serious I am about her learning Chinese." However, in response to the question, "do you speak Chinese with your child at home?" Zhang's mother said that she did not. She felt that using Chinese at home would contribute less to her child's learning outcomes. In addition, it was more effective to use English to discipline Zhang at home: "Sometimes, I just want her to get some jobs done quickly, and I do not want to waste time explaining the Chinese expressions." The home visits verified her statements regarding the home language. In conclusion, Zhang's mother exhibited great confidence in her selection of language-learning strategies.

\subsection{Zin's Parents' Language-Learning Strategies at Home}

Zin's parents are both full-time employees working for different companies. According to Zin's mother, Zin was raised by his grandmother. Zin's grandmother has lived with Zin's family for more than six years, supervising Zin and his sister's studies. Zin's parents finished their undergraduate studies in Mainland China and Zin's father was the first person in their family to be posted overseas. He was also the first green-card holder. Zin's mother accompanied her husband to the U.S. and finished her graduate studies at a U.S. business school.

Although Zin was born in the U.S., he lived in Mainland China for more than a year. Consequently, Zin's Chinese speaking and listening skills are superior to those of his peers at the Chinese heritage school. However, Zin's mother confessed that she played no role in Zin's language acquisition at home: "In fact, I did not have enough time to take care of Zin as he grew up. His grandmother was responsible for his education. Also, because we are living with Zin's grandmother, we have to speak Chinese at home."

According to Zin's mother, Zin's grandmother was always reading traditional Chinese poems to him as he grew up. She would ask him to recite some of the easier poems once he started to speak. "I believe that Zin has a gift for language learning," Zin's mother said. "He is good at imitating different Chinese dialects from TV, even though we never taught him any dialects at home. And I do not see any other child in the Chinese school who could do that."

When asked about the use of language-learning strategies at home, Zin's mother was confused about the concept of a "learning strategy." She felt that her busy working schedule left her with little flexibility to select an appropriate learning strategy. The family had to use either dinner time or TV time to teach Zin some Chinese characters. Most of the time, dinner time won. Zin loved Chinese food and his grandmother was very good at cooking. For this reason, Zin ate different Chinese dishes every day. The family preferred to teach Zin how to read the names of various Chinese dishes at the table. In doing so, they also imparted some knowledge of Chinese history and culture.

As Zin's mother emphasized, the family celebrated various Chinese festivals at home through cooking: "China 
has a very long history of cooking, we appreciate it, and it is an efficient way for Zin to remember different festivals." Both of Zin's parents have many relatives in China; they frequently communicate with family members in China via video conferencing. "I think it is a better way for Zin to practice his language too," Zin's mother said. "Also, it helps Zin to realize how important it is to learn Chinese well." Thus, in addition to using food and cooking to teach Zin Chinese at home, Zin's mother encourages him to participate in video conferences with their relatives in China every week. Zin's parents seize every opportunity to take Zin to various cultural events and celebrations organized by local Chinese associations. During each cultural event, they explain the theme or history of the event to him. Overall, Zin's parents emphasized the fact that they encourage Chinese learning and culture immersion at home. At the same time, they admitted paying less attention to Zin's homework and performance at the Chinese-heritage school.

Although the two families share similar attitudes about the importance of learning Chinese, their learning strategies are quite different. Table 1 summarizes different aspects of the learning strategies adopted by the two families.

Table 1. Differences in parental language-learning strategies

\begin{tabular}{ll}
\hline Zhang's mother's teaching strategies & Zin's parents' teaching strategies \\
- Supervise language assignments & $-\quad$ Speak only Chinese at home \\
- Watch Chinese movies/TV shows regularly & $-\quad$ Cook Chinese food \\
- Provide culture-related supplementary learning materials & $-\quad$ Celebrate Chinese festivals \\
- $\quad$ Pse an iPad to assist the child's Chinese acquisition & culture-related competitions and activities \\
Chinese value system & $-\quad$ Take the child to celebrations/Chinese festivals organized by the \\
- Praise the child for studying the history of China & community \\
& $-\quad$ Encourage the child to identify with China culturally \\
& and/or relatives in China \\
& $-\quad$ Take the child back to China for vacations \\
\hline
\end{tabular}

\section{Discussion}

Social interactions within their ethnic community influence the choices that CHL parents make in many aspects of their lives, ranging from the choice of furniture and daycare centers to the family language, and heritage-maintenance decisions (Berryman, 1983; Sakamoto, 2006; Li, 2006). The two families who participated in this research project came from the same community, in which Chinese people exhibit high ethno-linguistic vitality. Members of this community appreciate Chinese culture and tend to send their children to Chinese-heritage schools to receive formal language instruction ( $\mathrm{Li}, 2006)$. Positive social feedback from the community encourages parents to support bilingualism (Berryman, 1983; Sakamoto, 2006). Thus, the social context is crucial in influencing Chinese immigrant families' choice of heritage-language maintenance.

Alongside the influence exerted by their ethnic community, two other factors influence the choices made by Chinese immigrant families: the parents' perceptions of their heritage languages, and social interactions with people outside their own ethnic community. The results of this case study verify Li's (2006) conclusion that the manner in which heritage languages are perceived is critical to the choice of a home language. For example, Zhang's mother perceives Chinese as a foreign language — not a heritage language to use at home. She puts extra effort into preparing language assignments because she wants Zhang to perform well in "all the language tests at school." Parental language practices at home are vital to shaping their children's attitudes. Previous studies have shown that the literacy development of heritage learners is closely tied to their parents' perception of the "host society as well as the pragmatic and symbolic values they ascribed to the language" ( $\mathrm{Li}, 2006$, p. 357). Regardless of how much effort parents put into preparing supplementary learning materials, if they do not use Chinese at home, their children perceive Chinese as a second language, rather than a heritage language. If parents stop promoting heritage-language maintenance at home - or if there is no appropriate context in which learners can use the language-CHLs lose interest in language learning ( $\mathrm{Li}, 2007)$. Although the parents' perception of heritage-language learning may not guarantee success, it does affect the learning process.

The last factor is social validation from people outside one's own ethnic home community. During her interview, Zhang's mother constantly paused to inquire whether her language-learning strategies would be effective in fostering her children' literacy development. Similarly, during their interview, Zin's parents sought advice on 
how to teach Zin Chinese at home. Although the researcher does not come from the same ethnic community and is not a licensed public-school teacher, all of the study participants appeared to value her validation. Her feedback was apparently perceived as a heritage-maintenance knowledge base by these two immigrant families. This may reflect the researcher's educational background and work experience, which established her authority on language acquisition. It may also suggest that people outside their home community can have a strong impact on the language-learning strategies that parents choose to use at home.

This study attempts to answer the questions "what" and "why", while investigating the efforts of Chinese immigrant parents to promote heritage-language acquisition at home. However, many potential factors, both internal and external, remain unclear and require future study.

\section{Limitations and Future Directions}

The primary limitation of this research involves the data sources. The results rely on the coding of interviews and reflective memos. The researcher did not include observations of the two CHLs' literacy performance at the Chinese-heritage school, or evaluate their levels of ethnic awareness. As a consequence, these results cannot address the efficiency of learning strategies used at the home on CHLs, or assess their impact on the development of ethnic awareness among CHLs at public schools. Future researchers interested in different types of parental involvement should enrich the datasets and consider using surveys as a supplementary approach to explore the correlation between various language-learning strategies and literacy performance in school. They should also investigate the increase in ethnic awareness among CHLs. In sum, this case study aims to reveal the complexity of the Chinese community in U.S, and to promote awareness among licensed teachers of Chinese-heritage learners' funds of knowledge.

\section{References}

Baumrind, D. (1971). Harmonious parents and their preschool children. Developmental Psychology, 4(1), 99102. https://doi.org/10.1037/h0030373

Berryman, J. (1983). Immigrant children and the importance of self-esteem in second language acquisition. TESOL Talk, 14(4), 3-14.

Budiyana, Y. E. (2017). Students' parents' attitudes toward Chinese heritage-language maintenance. Theory and Practice in Language Studies, 7(3), 195-200. https://doi.org/10.17507/tpls.0703.05

Chao, R., \& Tseng, V. (2002). Parenting of Asians. In M. H. Bostein (Ed.), Handbook of Parenting (pp. 55-93). Hillsdale NJ: Erlbaum.

Chao, T. (1996). Chinese heritage community language schools in the United States. In X. Wang (Ed.) A view from within: A case study of Chinese heritage community language schools in the United States (pp. 7-14). Washington, DC: The National Foreign Language Center at the John Hopkins University.

Cheng, A. (2012). The Preliminary data and interviews from the database. Chinese Heritage Language \& Education Research in the United States: A U.S. Department of Education International Research \& Studies Grant. Toledo OH: University of Toledo.

Chinen, K., \& Tucker, G. R. (2006). Heritage language development: Understanding the roles of ethnic identity, schooling and community. In K. Kondo-Brown (Ed.), Heritage Language Development: Focus on East Asian Immigrants (pp. 89-126). Philadelphia, PA: John Benjamins Publishing. https://doi.org/10.1075/sibil.32.09chi

Cho, G. (2000). The role of heritage language in social interactions and relationships: Reflections from a language minority group. Bilingual Research Journal, 24(4), 333-348. https://doi.org/10.1080/15235882.2000.10162773

Cunningham, U. (2011). Growing Up with Two Languages: A Practical Guide for the Bilingual Family (3rd ed.). Florence, KY: Taylor and Francis. https://doi.org/10.4324/9780203814673

Feinberg, R. C. (2002). Bilingual Education: A Reference Handbook. Santa Barbara, CA: ABC-CLIO.

Glesne, C. (2011). Becoming Qualitative Researchers: An Introduction (4th ed.). Boston: Pearson.

Gu, Y. (2011). Towards an Innovation of Chinese Heritage School Teacher Education: A Need Analysis. Unpublished doctoral dissertation. Toledo, $\mathrm{OH}$ : University of Toledo.

He, A. W., \& Xiao, Y. (Eds.). (2008). Chinese as Heritage Language: Fostering Rooted World Citizenry. Honolulu, HI: University of Hawai; National Foreign Language Resource Center. 
Kondo-Brown, K. (2006). Heritage Language Development: Focus on East Asian Immigrants. Philadelphia, PA: John Benjamins Publishing Company. https://doi.org/10.1075/sibil.32

Lao, C. (2004). Parents' attitudes toward Chinese-English bilingual education and Chinese-language use. Bilingual Research Journal, 28(1), 99-121. https://doi.org/10.1080/15235882.2004.10162614

Li, G. (2006). Biliteracy and trilingual practices in the home context: Case studies of Chinese-Canadian children. Journal of Early Childhood Literacy, 6(3), 355-381. https://doi.org/10.1177/1468798406069797

Li, G. (2007). Home environment and second language acquisition: The importance of family capital. British Journal of Sociology of Education, 28(3), 285-299. https://doi.org/10.1080/01425690701252028

Li, J. (2003). U.S and Chinese cultural beliefs about learning. Journal of Educational Psychology, 95(2), 258267. https://doi.org/10.1037/0022-0663.95.2.258

Li, M. (2005). The role of parents in Chinese heritage language schools. Bilingual Research Journal, 29(1), 197207. https://doi.org/10.1080/15235882.2005.10162831

Sakamoto, I. (2006). When family enters the picture: The model of cultural negotiation and gendered experiences of Japanese academic sojourners in the United States. Cultural Diversity and Ethnic Minority Psychology, 12(3), 558-577. https://doi.org/10.1037/1099-9809.12.3.558

Sohn, S., \& Wang, X. C. (2006). Immigrant parents' involvement in American schools: Perspectives from Korean mothers. Early Childhood Education Journal, 34(2), 125-132. https://doi.org/10.1007/s10643-006-0070-6

Tse, L. (2001). Resisting and reversing language shift: Heritage language resilience among U.S. native bi-iterates. Harvard Education Review, 71(4), 676-708. https://doi.org/10.17763/haer.71.4.ku752mj536413336

Park, S. M., \& Sarkar, M. (2007). Parents' attitudes toward heritage-language maintenance for their children and their efforts to help their children maintain the heritage language: A case study of Korean-Canadian immigrants. Language, Culture and Curriculum, 20(3), 223-235. https://doi.org/10.2167/lcc337.0

Wang, M. (2003). An ethnographic study of Chinese heritage-language education and technological innovations. Journal of National Council of Less Commonly Taught Languages, 1, 69-94.

Wang, X. (Eds.). (1996). A View from Within: A Case Study of Chinese heritage Community Language Schools. College Park, MD: National Foreign Language Center.

\section{Copyrights}

Copyright for this article is retained by the author, with first publication rights granted to the journal.

This is an open-access article distributed under the terms and conditions of the Creative Commons Attribution license (http://creativecommons.org/licenses/by/4.0/). 